\title{
Creativity in an Occidental mode
}

The Poetry and Music of Science. Comparing Creativity in Science and Art, by Tom McLeish, Oxford, Oxford University Press, 2019, 355 pp., £25 (hardback), ISBN 9780198797999

\section{James Leach}

To cite this article: James Leach (2020) Creativity in an Occidental mode, Interdisciplinary Science Reviews, 45:1, 41-45, DOI: 10.1080/03080188.2020.1724378

To link to this article: https://doi.org/10.1080/03080188.2020.1724378

\section{Published online: 25 Mar 2020.}

Submit your article to this journal $\widetilde{ }$

Q View related articles $₫$

View Crossmark data $[\pi$ 


\section{Creativity in an Occidental mode}

The Poetry and Music of Science. Comparing Creativity in Science and Art, by Tom McLeish, Oxford, Oxford University Press, 2019, 355 pp., £25 (hardback), ISBN 9780198797999

This is a book of high ambition, masterfully realized. McLeish weaves a detailed and fascinating course through a long history of occidental arts and sciences with enormous skill, knowledge, and lucidity. The book is unique in my reading for several reasons, not least the sustained focus on retrieving, from accounts of the creative process and his own practice as a physicist, a distillation of stages in the creation of scientific knowledge that appears more hopeful, as well as more comprehensive in scope, than any other I am aware of. The final list of seven aspects of the process of creative thought ring true; a progression from vision and desire, through industry, the value of constraint, the incubation of ideas in unconscious and mysterious gestation, to illumination, verification, and arrival (305-307). But it is the journey to get to them, and in the process, their exploration and elaboration, which is so interesting. It elevates the book above many that purport to explain creativity. McLeish explores and follows the insights and understandings in the accounts of others, not as proof of a particular theory of mind or of perception (although these are sometimes elements of both his exposition and of those he draws upon) but as a movement of discovery through an astoundingly rich and satisfying terrain. The control, the depth, and range of knowledge of both arts and science, history and philosophy, the informative manner in which he links and elaborates, explains and gently directs attention, are remarkable. It is not an easy book. It is not a short book, and each chapter demands the reader's patience and perseverance, yet throughout, the return to emergent themes re-grounds and explains the reason for the chosen references and assists the reader in accompanying the author on this journey of discovery. The book is beautifully produced, a pleasure to hold and to read.

As this is just one among many reviews (and the frontispiece of the book itself draws upon many others), I will take the risky road of seeing what we might understand as the limits of the endeavour, a kind of critique that might be more provocative than another version of rephrasing and praising the achievement. I chose then not to make this a regular review, listing the contents of chapters and trying to be a reader for all those who will not read the book. It is too good and interesting in its own unfolding, as well as too dense, complex, and technical, for me to wish to attempt that.

If I have a critique, it revolves around two paradoxes. The paradoxes are firstly, that of attempting to write a democratizing treatise about creativity in science while focussing on the creative processes of outstanding individuals whose moments of brilliance have illuminated the western canon of both science and art (and who have made accounts of their processes). This is inevitably then a story of heroic figures. Secondly, that in the transcendentalist cosmology which McLeish draws upon and avows, where knowledge is an aspect of an instantiation of transcendence (of thought entering and comprehending nature), the separation of knowing from what is known is always re-inscribed. Because the focus is on the imaginative and creative in the occidental canon, there is little reference to the sense that creativity might happen or be institutionalized in 
different forms cross-culturally. This is fair enough. The book purports to engage with creative thought in science. It is, however, perhaps worth considering.

Firstly then, The Poetry and Music of Science offers every reader the chance to see their own moments of understanding and insight as exemplars of the processes he describes. McLeish writes,

There is no universal template for the narrative of creativity that maps onto every individual experience, but in as far as commonalities have emerged, it is at least possible to summarize a faithful mental and emotional story that scientists, scholars, and artists all recognise. (303-304)

Yet there is an inevitable impression that the creativity described is not the everyday creativity of human practice and action, but is that of the great scientist and artist or musician, of the moments and events in these disciplines that, as is often stated in the text, have changed or shaped the way western civilization and knowledge has developed. There is a grandness of scope and of reference here which is wholly understandable, but that does mark the book as of a particular kind of conversation, a treatise on those (usually men) whose processes of thought the author feels are revealing of the great advances of the western knowledge project. At several points, this mode of creativity is openly stated to be about a universal human capacity for and interest in understanding nature. I come back to this below.

The introduction draws the reader in with accessible descriptions of similar processes of creation and discovery as described by artists and scientists. Those famous figures whose practice appears to confirm the necessity for imagination and creativity, and whose writings or study give us some insight into how these are played out. Thus, we have Blake, Einstein, Popper, Shakespeare, Newton, Galileo, etc. Whether drawing attention again to these giant figures is helpful in all respects was often in my mind as I read. Because for all the truth that many of their practices are clearly the result of a blending of imagination and of the labour of both meticulous investigation and of leaps of faith, connection, and mysterious insight, their fame and prominence has not in fact done much to change the division between imagination in art and rigour in science that McLeish initially identifies as problematic. There is a very interesting and thorny problem here. In a book with this purpose and intent, to ignore them seems perverse. It is they who point the way. And of course, the manner in which attending to them sets up the problem for McLeish is brilliant: to paraphrase, 'these figures prove you need both imagination and creativity, and rigour, in making science and in making art, what we will do in this book is discover common underlying mechanisms of perception and method that prove what they appear anecdotally to show us'. It is also possible though that these conventional (in their non-convention or genius) figures also replay a familiar story about exceptionalism, about fortune and moment, and indeed, about some inherent qualities of particular human minds that could be as exclusive and chilling in their contemplation as the things science educators do.

At the very end of the book, McLeish turns, rather to my surprise, to the Book of Job and the wisdom about investigation and awe for God's creation that lies therein. As with the rest of this marvellous book, his writing is convincing, pertinent, and indeed, moving for the passion and insight that he brings to his endeavour. I say to my surprise, as the preceding 320 pages are devoted to the detailed and illuminating examination of the creative processes that various scientists, novelists, painters, and musicians have described for their work. But it makes perfect sense, not just thematically (a sense of wonder and awe at the beauty of creation infuses the book, and part of McLeish's 
purpose is to renew our, and coming generations, sense of this beauty and wonder, to demonstrate how it is accessible to the scientist just as readily as the artist). It makes perfect sense because far from just describing post-enlightenment experimental science, McLeish draws on the whole of the occidental tradition, of the history and development of engagement with Nature based on observation, enquiry, imagination, and rigour. The book does many things at once - describes, relates, engages, advocates, and illuminates. And what it illuminates is a huge swathe of human struggle to understand the world as an attempt to understand nature. In the face of the scope of this extended journey, and the open-hearted and generous nature of his vision, it is no wonder that the 'Two Cultures' argument seems so small-minded, indeed petty. McLeish has no time for it. Instead, he offers story after story, from classical antiquity to his own scientific breakthroughs that demonstrate not just correspondences between the arts and sciences, but their common foundation in human faculties of perception, imagination, and concentrated, one might even say, faithful, labour. He argues forcefully that science is not 'exclusively modern',

claiming science as an exclusive property of the modern world removes the deep and slow cultural development of an imaginative and creative engagement with nature that develops, at least chronologically, alongside the story of art in its own multitude of forms. (12)

I wish though to dwell for a moment upon the very occidental nature of the endeavours he describes. By occidental, I mean to solve the manner of my surprise at seeing Job discussed at the end of the book. For what we are looking at here is a passionate and persuasive treatise to reintegrate an understanding of nature into human knowledge and practice. The separation is the problem, and that marks the endeavour as one historically, and dare I say, culturally, situated in the transcendental Judeo-Christian tradition, albeit at the beginning of the twenty-first century. The problem is man's separation from nature, from God, and from knowledge. McLeish's solution, as I say above, is to advocate and illustrate the ways that through creative thought in science, we might work to heal not just what he describes as 'the division we are seeking to understand and to mend' (207), the separation between academic disciplines into arts, humanities, and sciences, but our very relationship to the earth and to knowledge itself.

The reason that human beings set their mind to comprehending the natural world is that a state of vision and understanding is both their origin and their destiny. To read and to re-imagine the world is to engage with a task of recovering original knowledge, at an almost divine level of insight, lost when humankind rejected this calling. (324)

The emergence of 'nature' as a subject for both art and science is a central theme of the book. What though of those places and peoples for whom the notion of 'nature' is absent, or is conceptually differently constituted (i.e. not as something separate from the human mind and human artifice)? If both art and science share the same processes of gestation and production (as this book convinces), and these processes require or assume that what the imagination works with and on is 'nature', then does this mean that in such places where there is no nature, there is no creativity, no innovation, or knowledge? Perhaps just no art and science? McLeish's narrative is of the grand history of western arts and sciences, thus allowing to fall by the wayside not only, as above, the possibility of the everyday creativity of human social life, but also of those places and times which fall outside the purview of those who position themselves as the custodians, or the descendants, of these great acts of creation. 
Continuing in the introduction to muse on the divisions between the sciences and the arts as disciplines, while maintaining all the while a promise that these can be overcome by understanding the fundamentally similar processes that are involved in making art and making science, McLeish draws upon George Steiner, and dwells on his phrase 'the sheer inhuman otherness of matter'. He returns to it in the conclusion. The point is complex, as McLeish rather agrees that art offers insights into the world of nature that illuminates science and that scientists can emulate, but in fact, his point is that they do emulate them. Whereas for Steiner, art is the only suitable vehicle, for McLeish this position is based on a misrepresentation of the real work of science. Steiner's words recall, by analogy if not content, Ingold's recent complaints (in the pages of this journal) against mechanistic, commodified science, and his assertions of art's greater capacity to offer involvement with and comprehension of 'life' 'in the world'. But whereas for Ingold this realization demands a reconsideration of 'matter' itself as part of the flow of life, something that is not separate from our capacity for engagement but constitutive of it, and an attendant basic rethinking of the mechanical approach 'to' matter, for McLeish the perception that science is not creative is all a matter of misunderstanding. For him in this book, (good) science draws upon exactly parallel processes of conception, invention, responsiveness, and engagement with 'the beauty' of the world as does art. Yet the mystery of 'matter', or nature, remains there to be investigated and understood. Its 'otherness' is the spur and reason for investigation.

There is something at least worth pausing over about starting from (and returning to) the differences between matter and thought, between given nature and creative engagement with it. For many anthropological commentators, it is exactly the convention of nature as separate from culture or of the assumed difference between conscious life and unconscious matter, that gives rise to the conceptual division between art and science as functional and utile on the one hand, and as useless subjectivity on the other. Where McLeish writes:

We have failed to communicate the adventure of re-imagination and learning, of nature's invitation to peer into the world's multiple levels of structure, to extend our sense of vision in manifold ways, think about matter and form in entirely new ways, (31)

he retains 'nature' as that which science and art attend to as something beyond and outside the human (although he acknowledges the paradox of this position). 'The theme of duality has haunted our hunt for the sources of creativity in the sciences' (261). 'Yet there is an inherent distancing in the very act of declaring the world an object, ourselves as observing subjects' (333). These are consequences of what I am here calling the transcendental view of knowledge and matter as separate.

What then of those documented places and times where the nature/culture distinction does not hold, does not form the basis for thought or for understanding the place of man in the cosmos? Where the problems of life are never about recalcitrant matter and the joy of life not in understanding it, but where what is problematic are always other people, and the joy of life is in moving in flow with them? In ending this response, I turn for a moment to the implications of the existence of such a place. Of a creativity that is distributed across the living world itself and of which humans participate but do not control. A place where the transcendence of the JudeoChristian knowledge tradition comes to look like what it is, a specific and self-constituting transcendence that produces exactly the matter of its concern. It is in its desire to universalize, to make universal truth, that this self-transcendence is most apparent. We hear the stories of the great composers and physicists, novelists, and painters in 
the book 'within a universal narrative of creativity' (259). A transcendentalist knowledge tradition encompasses its others. Yet they remain, and equally deserve our attention to their integrity.

Consider just for a moment a place where everything that is human is a human creation, where humans are human because they take responsibility for creating and recreating the world through their disciplined practice and activity. Where, in other words, there is no transcendence, only variations on how and where human life, and knowledge, comes into being and has effect. This is no paradise, as responsibility is not just for life but for death, where misfortune and sickness are also always caused by and attributable to other people and beings. But we are not in the game of judging between human worlds here, merely of pointing out that there are places where nature is not outside or beyond human thought. Where matter is not an intractable other but is exactly what is engaged and lived through in the processes of life and death. Knowing matter is also part of one's own constitution as a being on the same plane. Matter responds, has effects, is, in fact, as potentially animate and agentive as human thought. In such a place, knowledge and responsibility are just differently constituted, and creativity is the condition of life itself as life requires the continual recreation of the conditions of humanness. People in such places just do not have the same problem of how 'to overcome an intransigent divide between reasoning subject and sensed object' (334). The anthropological literature documents just such ways of being human as also real and existent.

A conventional reading of Job might be that he is a man who suffers God's power and realizes his helplessness in the face of that power. The power of God is transcendent, and there is nothing that humans can do about that. McLeish's more nuanced and hopeful reading is that there is an invitation within the story over and over again to attend to and love the beauty of creation and realize part of divine transcendence through our labour of investigation and knowledge; to partake at times of that transcendence through knowledge. To approach, 'the possibility of a regained deep knowledge of nature' (324) is in fact a promise of redemption. What The Poetry and Music of Science does is lay out a remarkable treatise for such an endeavour, one that sees neither science nor art as exclusive, but that utilizes processes and practices, and the God-given gift of being human, to achieve this end. It is brilliant within its scope - the vast and complex development of the Judeo-Christian influenced knowledge tradition. 'The "Narrative of the Creative Act", with its seven chapters and empirical universality, might qualify as one of the great human stories in itself (305). Without wishing to sound pat, this is also its limitation. It is a story of the development of a particular knowledge form, a rich resource then not only for practitioners of the sciences, but also for those who wish to contemplate, ethnographically as it were, the historical development and the contours of this one, specific form of knowing (and being), and the place of creativity in a transcendentalist mode.

James Leach

CREDO, Maison Asie-Pacifique, Aix Marseille Université, 3, place Victor Hugo, 13003

Marseille, France

CREDO - UMR 7308; AMU-CNRS-EHESS, Centre de Recherche et de Documentation sur

l'Océanie, Marseille, France

School of Social Science, The University of Western Australia, Perth, Australia

Q james.leach@pacific-credo.fr (1) http://orcid.org/0000-0002-5410-3545

(C) 2020 James Leach

https://doi.org/10.1080/03080188.2020.1724378 